\title{
Information Technology and the Work/Cultural Orientations of Americans, Mexicans and Germans
}

\author{
John E. (Jack) Merchant and Sylnovie Merchant \\ School of Business and Economics, Lynchburg College, \\ Lynchburg, VA, USA
}

\author{
merchant.j@lynchburg.edu merchant.s@lynchburg.edu
}

\begin{abstract}
From a business perspective, the political and economic effectiveness of the United States in the global market-place will depend on individual abilities to communicate with people from other cultures. Most multinational corporations have one individual from one culture managing employees from other cultures. This has led to conflict, law-suits, and reduced productivity. To date, US business people sent overseas have not fared well compared to their counterparts from Europe and Asia, primarily because of cultural conflicts. The future success of American business, therefore, is its ability to interact with other cultures and to understand the orientations of these individuals.
\end{abstract}

Keywords: cultural values, work values

\section{Introduction}

The importance of Information Technology (IT) on firms has increased significantly within the last two decades. More and more IT has become the tool used by corporations to be more competitive. For example, IT (1) has shortened the product life cycle in the publishing industry, (2) changed the relationship of buyer and seller in the banking industry, (3) increased market share to over 50 percent for American Airlines in the airline industry, and (4) increased profits due to customer loyalty in the Hospital Supply industry (Mahmood \& Soon, 1991). Much earlier, in an application to create new business level strategies, IT has been used from the perspective of the value-added-chain, linking with supplies on one end and handling information processing for customer accounts on the other (Rockart \& Scott Morton, 1984).

While it is understood, and accepted, that IT does influence an organization, there is no agreement on what elements need to be explored concerning the influence of IT on the organization.

Material published as part of this publication, either on-line or in print, is copyrighted by the Informing Science Institute. Permission to make digital or paper copy of part or all of these works for personal or classroom use is granted without fee provided that the copies are not made or distributed for profit or commercial advantage AND that copies 1) bear this notice in full and 2) give the full citation on the first page. It is permissible to abstract these works so long as credit is given. To copy in all other cases or to republish or to post on a server or to redistribute to lists requires specific permission and payment of a fee. Contact Publisher@InformingScience.org to request redistribution permission.
The arguments are that (1) the internal condition that support strategy utilization include leadership, integration of IT, the strategic function and direct contact between IT and line divisions (Johnston \& Carrico, 1988); (2) one needs to look at individual action and behavior in an organizational context (Swanson, 1987); and (3) technology, interdepartmental relations and the envi- 
ronment are the key factors in the transformational process (Daft \& Lengel, 1986). This lack of agreement is understandable because the level of complexity inherent in any organization is a characteristic of the system $=\mathrm{s}$ structure, and it is impacted by the total number of its individual sub-units, the number of different layers in the structural hierarchy, the number of different business processes that perform business activities, and the number and strengths of connections among all these sub-units, and between these sub-units and outside economic agents.

A consequence of this lack of agreement is that researchers are left to suggest and develop their own approach to studying the influence of IT on an organization. As Delone and McLean (1991) noted "... no single measure is intrinsically better than another; so choices of a success variable is often a function of the objective of the study, the organizational context, the aspects of the IS which is addressed by the study, the independent variables under investigation, the research method, and the level of analysis (i.e., individual, organization, or society)."

\section{Individual Cultural Orientations}

Individuals bring cultures of origin to work (Gibson \& Zellmer-Bruhn, 2001) that reflect their particular ongoing histories in various cultural contexts, such as national cultures. Cross-cultural research has established that in addition to national culture explaining variations in attitudes, it is also related to social behaviors such as aggression, conflict resolution, social distance, helping, dominance, conformity, and obedience, as well as decision-making and leadership behaviors (Gannon et al, 1994; Gibson \& Zellmer-Bruhn, 2001; Hofstede, 1980; Shane, 1994; Triandis, 1994). In cognitive terms, national culture is viewed as a set of shared meanings transmitted by a set of mental programs that control responses in a given context (Hofstede, 1980; Shweder \& LeVine, 1984). The basic thesis of a cognitive approach to culture is that processing frameworks acquired in one culture persist and influence behavior even though circumstances change. In this manner, culture guides our choices, commitments, and standards of behavior (Erez \& Earley, 1993)

It is not enough to suggest that concepts vary across organizational cultures; it is also important to examine systematic variation due to specific aspects of culture. Researchers have demonstrated that patterns of orientations (O'Reilly, Chatman, and Caldwell, 1991; Kabanoff, Waldersee, \& Cohen,1995; Kabanoff and Holt, 1996) and practices (Hofstede et al., 1990) can be used to explain the differences in organizational cultures. Kabanoff and colleagues ( Kabanoff, Waldersee, \& Cohen,1995; Kabanoff and Holt, 1996) identified a set of nine orientations-performance, reward, authority, leadership, teamwork, commitment, normative orientation, participation, and affiliation - that can be discerned from organizational documents such as annual reports and demonstrated that different patterns of orientations were associated with different ways of portraying and communicating change.

Other authors showed that individual performance varied depending on the cultural background of the group studied. For instance, the collectivistic orientation of Chinese workers suggests more of a tendency toward group-based performance incentives than Americans (Earley, 1993).

The purpose of this paper is to suggest one area for research of the relationship of IT to organizational cultural variables and to the orientations of employees around the world. It presents the results of research of the cultural orientation of American and foreign employees. At the same time, it suggests that the "perceived" right of an individual is to behave according to his/her cultural orientation. The starting point of this discussion is the model detailed by Rockart and Scott Morton (1984) (Figure 1). 


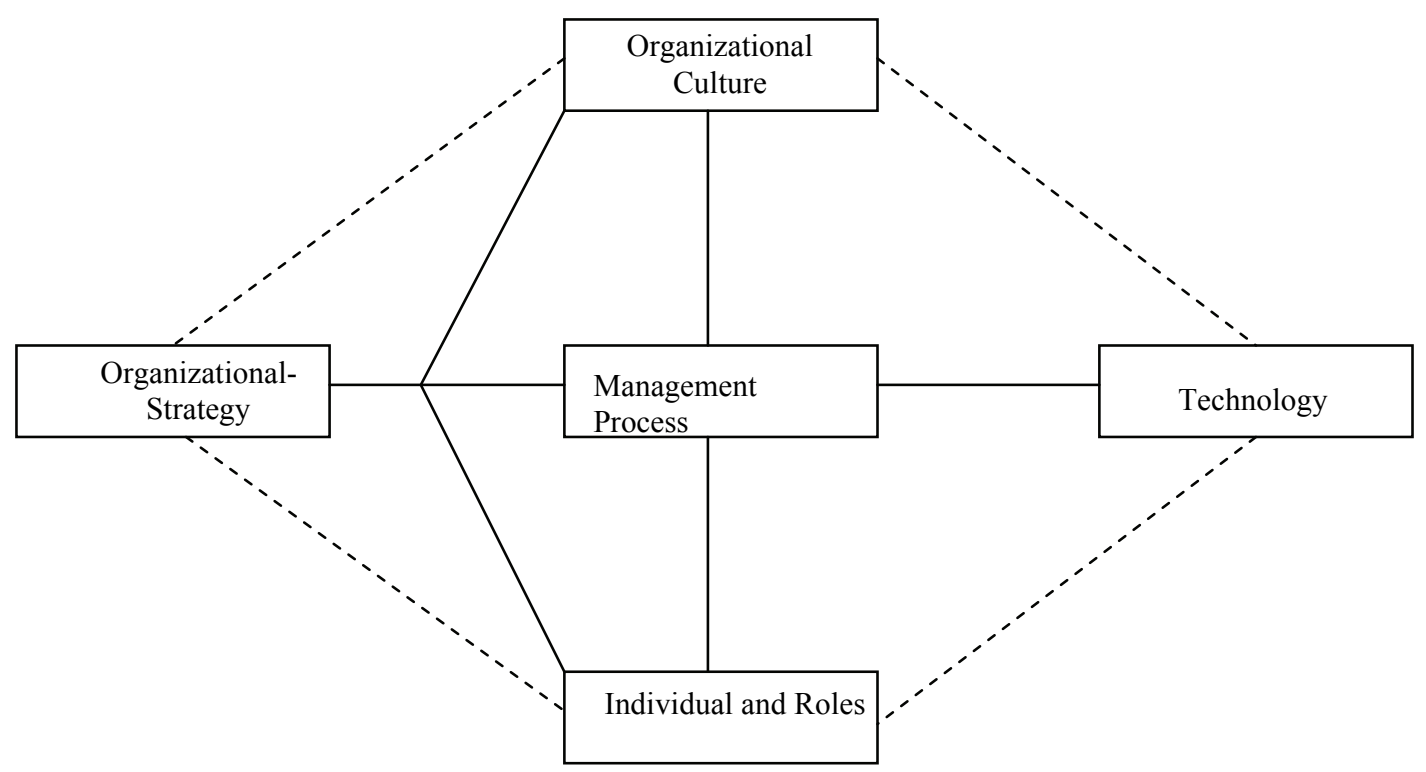

Figure 1 - Conceptual Impact of IT

Adapted from Rockart and Scott-Morton (1984)

\section{Organizational Culture}

The model by Rockart and Scott Morton (1984) shows the key elements needed to study and understand the relationship of IT to the people in the organization and on the success of the firm. The center of the model is identified as the "Management Processes." It is central to their study because it is viewed of the part that holds the organization together (Rockart and Scott Morton, 1984). More importantly, however, is the fact that the authors

“...have added to organizational structure the very important dimension of corporate culture. ...it is much of what makes some firms thrive and others, which have an identical structure and are similar in most other respects, merely survive" (p. 91).

While some may consider it an ill-defined, illusive term, culture has been operationally defined in relation to corporate strategy by many students of the concept. Mintzberg et al. (1995) define it as "... made up of intangible things that are shared by the people in an organization - values, beliefs that guide action, understandings, even ways of thinking." Hunger and Wheelen (1996) state that "Culture is the collection of beliefs, expectations, and values learned and shared by a corporation=s members," while Yip (1995) indicates that "Culture is made up of intangible things that are shared by the people in an organization - values, beliefs that guide action, understandings, even ways of thinking." The keys terms here are the values and expectations that individuals bring into the workplace.

\section{Culture Benefits and Types}

The benefits for an organization that matches culture and IT is that an optimal culture:

a) conveys a sense of identify for employees;

b) helps generate employees $=$ commitment to something greater than themselves;

c) adds to the stability of the organization as a social system; and 
d) serves as a frame of reference for employees to use to make sense out of organizational activities and to use as a guide for appropriate behavior (Hunger \& Wheelen, 1996).

In discussing the theories on how IT affects organizational life, Markus and Robey (1988) indicate the difficulty in constructing beliefs about the nature of causality as because it requires a detailed understanding of the dynamic organizational process as well as addition to knowledge about the intentions of individuals and the features of IT. While most people will agree that it is difficult to draw the clear relationship of causality, it is not impossible, and various models or schemes can be proposed in order to investigate these relationships.

That is, the preceding discussion suggested that there is a strong relationship between IT adoption and use and organizational culture. In other words, as one author indicates, the nature of the firm. That is, as Fiedler et al. (1996) pointed out, the key contribution of IT is to support the firm. This can only be achieved if the capabilities and characteristics of the IT structure matches the requirements and the nature of the organization.

\section{Current Research}

This research approach parallels the model proposed by Orlikowski and Robey (1991), especially as it relates to IT Development, IT Application and the relationship to the culture and individuals in the organization. They proposed four factors that are central influences in the relationship of IT to the structure of the organization. First of all, they point out that IT is the product of human action. For that reason, it will tend to reflect the assumptions and objectives of its designers and engineers. More importantly, IT is not effective in facilitating substantial organizational action, unless it is used. Therefore, while humans can design and introduce IT for use in the organization, unless individual users perceive its benefits for them, it will not be totally effective in achieving its design.

This is because, as the authors point out in their second dimension, IT is the medium of human action, and, therefore, in order to be utilized, it has to be appropriated by humans. There is always the possibility that humans may choose not to use the technology or they may use it in ways that circumvents its "normal" operation.

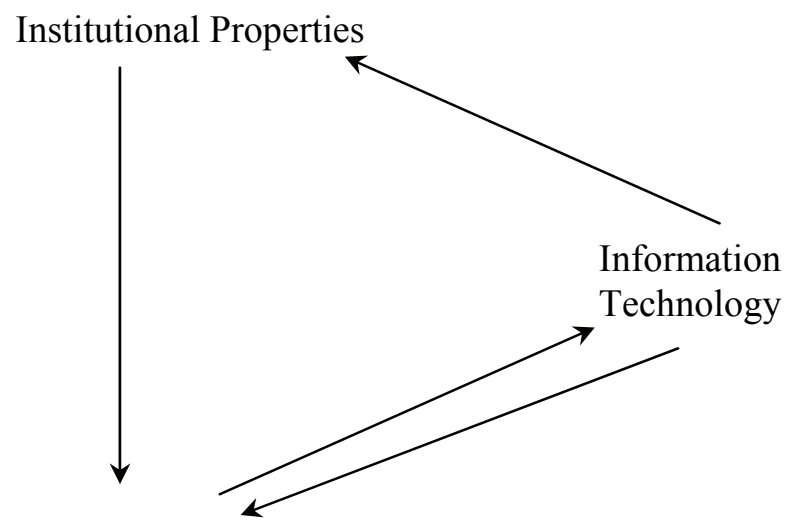

Human Actors

Figure 2 - Situational Model of Information Technology

Adapted from Orlikowski and Robey (1991 
Relatedly, the third influence in their model, the "conditions of information technology interaction, point out that because humans do not work in a vacuum, they are influenced by the values, power, culture, etc, that surround them." The final influence of their model involves the "consequences of IT interaction," and with it determines the success or failure of the organization to promote its interests. Their model of the four relationships is shown in Figure 2.

It is interesting to note that their model only shows Institutional Properties impacting on Human Actors. As we are suggesting, however, Institutional Properties would also impact on Information Technology.

\section{Cultural Orientations}

For the purposes of this paper, we rely upon a conceptual framework outlined by Harrison (1975) to discuss organizational culture. Mintzberg et al. (1995), to a large degree, used an adaptation of Harrison"s model. Harrison offered four organizational ideologies: (1) Power Orientation, (2) Role Orientation, (3) Task Orientation, and (4) Person Orientation.

The Power-Oriented organization wants to dominate its industry, is extremely competitive and desires to have employees loyal and supportive, while it will be the benevolent authority for all. In some societies, employees feel very comfortable in this type of environment - that is, follow the lead of the boss.

The Role-Oriented organization aspires to be rational and orderly in all of its dealings. There is a preoccupation with legality, legitimacy, and responsibility. Employees are expected to follow the detailed policies and procedures of the organization, and in many cases, insist upon it.

The Task-Oriented organization strives to achieve its goals. The important and determining factor is that the organization's structure, functions, and activities are all evaluated in terms of their contribution to achieving the desired goal. Nothing is permitted to get in the way of accomplishing the task.

Finally, the Person-Oriented organization exists primarily to serve the needs of its members. The organization attempts to provide growth to its members by recognizing that a more experienced, trained individual will contribute more to the organization.

The strength of Harrison's framework is twofold. One, he has developed a valid and reliable instrument that can be used to classify the four cultures, and has been used to predict success in joint venture organizations in information technology (Cartwright \& Cooper, 1989), and compare different cultures from a strategic standpoint (Merchant, 1997). Two, he has provided the basis for the potential benefits for both the organization and the individual operating under the four cultures. For individuals, the characteristics of the four cultures provide them with varying degrees of: (1) security against economic, political, and psychological deprivation, (2) opportunities for voluntary commitment to worthwhile goals, and (3) opportunities to pursue one's own growth and development independent of organization goals. In essence, one can assess the compatibility of individuals and the four types of cultures. Table 1 reflects these relationships. 
Table 1: Interests of People

\begin{tabular}{|l|c|c|c|}
\hline ORIENTATION & $\begin{array}{c}\text { Security against economic, } \\
\text { political and psychological } \\
\text { deprivation }\end{array}$ & $\begin{array}{c}\text { Opportunities for Vol- } \\
\text { untary commitment to } \\
\text { worthwhile goals }\end{array}$ & $\begin{array}{c}\text { Opportunities to pursue } \\
\text { one's own growth sepa- } \\
\text { rate from firm's goal }\end{array}$ \\
\hline POWER & Low & Low & Low \\
\hline ROLE & High & Low & Low \\
\hline TASK & Moderate & High & Low \\
\hline SELF & High & High & High \\
\hline
\end{tabular}

For organizations, the four cultures provide them with varying degrees of (1) effective response to dangerous, threatening environments, (2) dealing rapidly and effectively with environmental complexity and change, and (3) internal integration and coordination of effort, if necessary, at the expense of individual needs. In essence, selecting one culture over another may serve the interests of the organization better in its competition with rivals. Table 2 reflects these options.

Table 2: Interests of the Organization

\begin{tabular}{|l|c|c|c|}
\hline ORIENTATION & $\begin{array}{c}\text { Effective response to } \\
\text { dangerous \& threaten- } \\
\text { ing events }\end{array}$ & $\begin{array}{c}\text { Dealing rapidly and ef- } \\
\text { fectively with complexity } \\
\text { \& change }\end{array}$ & $\begin{array}{c}\text { Internal unity - if nec- } \\
\text { essary at the expense } \\
\text { of people }\end{array}$ \\
\hline POWER & High & Moderate to Low & High \\
\hline ROLE & Moderate to Low & Low & High \\
\hline TASK & Moderate to High & High & Moderate \\
\hline PERSON & Low & High & Low \\
\hline
\end{tabular}

\section{Methodology and Data}

Survey variables as developed by Harrison were administered to employees in American, Mexican and German corporations. Demographic data included martial status, gender, length of employment, public or private sector, educational level, organizational position, etc. A total of 130 American, 100 Mexican, and 201 German responses were collected, which measured twelve cultural variables. These included such items as (1) type of boss desired, (2) how decisions should be made in an organization, and (3) how conflict should be resolved, etc.

\section{Findings}

The findings placed American workers clearly into the Task orientation culture. In fact, of the 12 variables studied, 10 fell into the Task category, clearly indicating that Americans prefer to be given a job to do, be provided with the proper support, and then left alone to accomplish what they feel that are qualified and competent to do. For the Mexicans, their primary cultural orientation is Person, or Self. Clearly, they desire an environment where their personal interests are considered and that activities revolve around that aspects that help them grow as a person. For the Germans, their orientation is definitely Role. They obviously desire a work environment where things are impersonal and correct, insisting on abiding by the formal system in effect; that is, clearly spelled out roles, rules and responsibilities.

One example of the three differences is in how they define what a good boss is to them. For the Americans, a good boss is one that is "egalitarian, using his authority to obtain the resources needed to complete the job." For the Mexican, a good boss is one that is "strong, decisive, firm, fair, protective, generous, and indulgent to loyal subordinates." On the other hand, for the Ger- 
mans, a good boss is one that is "impersonal and correct, demanding from subordinates only that which is required by the formal system." Another example is the orientation of the three nationals where decisions need to be made within an organization, such as introducing a new process, or procedures. Americans feel that decisions be made by the "person with the most knowledge and expertise about the problem," while the Mexicans feel that it should be made by the "person most personally involved and affected by the outcome," and the Germans value decisions should be made by the "person whose job description carries the responsibility." In relation to the Interests of the Individual and Interests of the Organization cited above, a corporation with a Task Orientation is the best for dealing with the external environment, dealing with change, and achieving a moderate degree of internal unity. From the IT standpoint, therefore, when introducing or using IT in that type of organization, one can tentatively conclude that it is most beneficial to emphasis the role of the employee's sense of responsibility and initiative and structure one's operation around them - rather than rely upon detailed rules, regulations, and procedures as would be required by the Germans in a Role Orientation culture, or the personnel needs of the employees as desired by the Mexicans.

From the interests of the employees viewpoint, Americans are happy in a Task Oriented corporation as it provides them with (1) a moderate degree of Security against economic, political and psychological deprivation, (2) a high degree of opportunities for voluntary commitment to worthwhile goals, (3) a high degree of opportunities to pursue one's own growth separate from the firm's goal. Conversely, they have only a moderate degree of internal unity, even at their expense, from the corporation.

For the Germans, their Role orientation has (1) a high level of security, but (2) a lack of voluntary opportunity, and (3) a low level to pursue their own goals.

For the Mexicans, a Self orientation provides them with high degrees of (1) security, (2) a high degree for voluntary commitment, and (3) a high degree to pursue their own goals.

The issue for all employees, however, is if their orientation conflicts with the corporation=s dominant orientation, there will be strife, a violation of their perceived rights and major internal conflicts. The major conclusion is that Management must understand the cultural orientation of their employees and treat them accordingly.

\section{Conclusions}

From this research, it became apparent, as Orlikowski and Baroudi (1991) indicated, that various research philosophies can offer a perspective on the phenomena of interest in information systems research. Researchers of IT have made great strides in identifying and isolating those variables which can advance the study of information technology and its contribution to the success of an organization. This practice needs to continue and all internal and external variables which could have an impact on the potential success of an organization need to be considered in order to promote the use of IT for the good of the organization and the individuals in the organization. This research can make a contribution to the study on the influence culture and IT on an organization.

Fiedler et al. (1996), stated that more research is needed into the benefits of matching IT and organization culture. This research will contribute to the advancement of IT and organizational success, in that IT is both social and material properties because it has been physically and socially constructed by subjective human action, while also objectified through institutionalization (Orlikowski \& Robey 1991). While we do not have any record, so far, of legal actions revolving around the violation of one's cultural rights and orientation, it appears to be an area that could become extremely important in cross-cultural management situations. Therefore, managers in- 
volved in cross-border interactions with culturally oriented individuals need to be cognizant of the existence of these potential problems and take the steps to understand other cultures.

\section{References}

Daft, R.L. \& Lengel, R.H. (1986). Organizational information requirements, media richness and structural design. Academy of Management Journal, 32(5), 554-571.

DeLone, W.H. \& McClean, E.R. (1992). Information systems success: The quest for the dependent variable. Information Systems Research, 3(1), 60-90.

Cartwright, S. \& Cooper, C.L. (1989). Predicting success in joint venture organisations in information technology. Journal of General Management, 15(1), 39-52.

Ein-Dor, P. \& Segev, E. (1978). Organizational context and the success of management information systems. Management Science, 24(10), 1064-1077.

Fiedler, K.D., Grover, V. \& Teng, J.T.C. (1996). An empirically derived taxonomy of information technology structure and its relationship to organizational structure. Journal of Management Information Systems, 13(1), 9-34.

Gannon, M. J. (1994). Understanding global cultures. Thousand Oaks, CA: Sage.

Harrison, R. (1975). Understanding your organization's character. In Harvard Business Review On Management (199-209), New York: Harper \& Row.

Hofstede, G. (1980). Culture's consequences; International differences in work-related values. Beverly Hills: Sage Publications.

Hofstede, G. (1993). Cultural constraints in management theories. Academy of Management Executive, $7(1), 81$.

Hofstede, G. \& Bond, M.H. (1988). The Confucius connection: From cultural roots to economic growth." Organizational Dynamics, Spring, 5.

Hunger, J. D. \& Wheelen, T.L. (1996). Strategic management. New York: Addison-Wesley.

Johnston, H. R. \& Carrico, S. R. (1988). Developing capabilities to use information strategically. MIS Quarterly, 12(1), 37-88.

Mahmood, M.A. \& Soon, S.K. (1991). A Comprehensive model for measuring the potential impact of information technology on organizational strategic variables. Decision Sciences, 22(4), 869-897.

Markus, M.L. \& Robey, D. (1988). Information technology and organizational change: Causal structure in theory and research. Management Science, 34(5), 583-598.

Merchant, J.E. (1997). Determinants of corporate success: One view of comparative work values of Australians and Americans. Proceedings of the Fourth International Meeting, Decision Sciences Institute, Sydney, Australia, July, 1997.

Mintzberg, H., Quinn, J. B. \& Voyer, J. (1995). The strategy process. New Jersey:.Prentice-Hall.

Orlikowski, W.J. \& Baroudi, J. (1991). Studying information technology in organizations: Research approaches and assumptions. Information Systems Research, 2(1), 1-28.

Orlikowski, W.J. \& Robey, D. (1991). Information technology and the structuring of organizations. Information Systems Research, 3(2), 143-169.

Rockart, J.F. \& Scott-Morton, M.S. (1984). Implications of changes in information technology for corporate strategy. Interfaces, 14(1), 84-95.

Shane, S. (1993). Cultural influences on national rates of innovation, 9, 59-73.

Swanson, E. B. (1987). Information systems in organization theory: A review. In Critical Issues in Information Systems Research (pp. 181-204). John Wiley and Sons. 
Tushman, M.L. \& Anderson, P. (1996). Technological discontinuities and organizational environments. Administrative Science Quarterly, 31, 439-465.

Yip, G.S. (1995). Total global strategy. New Jersey: Prentice-Hall.

\section{Biographies}

Jack Merchant is currently a Visiting Professor of Management at Lynchburg College; previously he taught for over 20 years at California State University, Sacramento as a Professor of Strategic Management, and for 5 years at the United States Air Force Academy. He was inducted as a Fellow into the World Academy of Productivity Sciences in 1998. Besides Strategic Management, he specializes in International Business and has done considerable research into the cultural orientations of employees around the world.

Sylnovie Merchant is currently an Associate Professor of Information Systems and Production at Lynchburg College; previously she taught for 5 years at California State University, Sacramento. She is the recipient of many honors, including the KPMG Scholars Award, and the Forgivable Loan Program of California State University to obtain her Doctorate at the University of Arkansas. 